\title{
Nursing work intention, stress, and professionalism in response to the COVID-19 outbreak in Iran: A cross-sectional study
}

\author{
Hamed Zandian ${ }^{\mathrm{a}, 1}$, Minoo Alipouri Sakha ${ }^{\mathrm{b}, 2}$, Elhameh Nasiri ${ }^{\mathrm{a}, 3}$ and Telma Zahirian Moghadam ${ }^{\mathrm{a}, 4, *}$ \\ ${ }^{a}$ Ardabil University of Medical Sciences, Ardabil, Iran \\ ${ }^{\mathrm{b}}$ Iran University of Medical Sciences, Tehran, Iran
}

Received 12 November 2020

Accepted 5 January 2021

\begin{abstract}
.
BACKGROUND: Professionalism, stress and demographic factors are the three key influences in nurses' intention to provide care.

OBJECTIVES: This study examined the levels of work intention, stress and professionalism of nurses and determine the relationship between nursing work intention and factors in response to COVID-19.

METHODS: This cross-sectional study was conducted on 362 nurses from COVID-19-devoted hospitals in Iran. A selfadministered electronic-based questionnaire was developed and used to determine levels of stress, professionalism, and nursing intention. Multiple regression analysis was carried out to analyze the correlation between nursing intention with respect to stress and professionalism.

RESULTS: The overall stress, professionalism, and nursing intention scores were 48.56, 21.46, and 17.83 respectively. There were significant differences in nursing intention scores between gender, marital status, and having training groups $(p<0.05)$. The regression analysis revealed that nursing intention had a significant relationship with older age $(p<0.001, \mathrm{~S} . \mathrm{E}=1.11, \mathrm{~B}=17.02)$, higher income level $(p<0.001, \mathrm{~S} . \mathrm{E}=1.81, \mathrm{~B}=6.98)$, having previous training $(p=0.008$, $\mathrm{S} . \mathrm{E}=1.22, \mathrm{~B}=3.27)$, higher stress level $(p<0.001, \mathrm{~S} . \mathrm{E}=2.37, \mathrm{~B}=-21.39)$, and high professionalism level $(p<0.001$, $\mathrm{S} . \mathrm{E}=1.16, \mathrm{~B}=11.99)$.
\end{abstract}

CONCLUSION: Having an adequate staff requirement plan, planning appropriate training for nurses, and proactive psychological support are crucial to prevent burnout and continue to provide nursing services.

Keywords: Work intention, coronavirus, hospital nurses, emotional stress

\footnotetext{
${ }^{1}$ ORCID: 0000-0002-1284-5823

${ }^{2}$ ORCID: 0000-0002-9318-7075

${ }^{3}$ ORCID: 0000-0003-3897-1278

${ }^{4}$ ORCID: 0000-0003-1290-4202

*Address for correspondence: Telma Zahirian Moghadam, Social Determinants of Health Research Center, Ardabil University of Medical Sciences, Ardabil, Iran. Tel.: + 98912648 4037; E-mail: t.zahirian@gmail.com.
}

\section{Introduction}

Nurses are the largest group of health team employees in the health care delivery system in Iran. The quality of health care is largely depend on the service provided by nurses [1]. The nursing profession endures a great deal of job stress due to the need for high skills, concentration on work, strong teamwork and 24-hour care [2]. The nurses dealing with infec- 
tious disease patients are more stressed because they face an increased size and intensity of their work, and are forced to implement new protocols [3].

Emerging infectious diseases have been first recognized in human hosts, originated in one region of a country, and rapidly transmitted to related populations in other countries due to globalization [4, 5]. Examples of contagious diseases are influenza $\mathrm{A}$ (H1N1) with new swine origin in Mexico, Ebola in Guinea, Middle East respiratory syndrome (MERS) in Saudi Arabia, and SARS in China, which resulted in 9.9 to 90 percent fatalities [6]. The recent emerging infectious disease that has have a global impact is COVID-19. The disease was first reported on December 31, 2019, in Wuhan, China, and according to the World Health Organization, COVID-19 has been spread all over the world [7].

Out of 100, about 80 COVID-19 infected patients recover without the need for any special treatment. Though, one in six people with COVID-19 become seriously ill and experienced difficulty in breathing. Older people and people with underlying conditions such as high blood pressure, heart problems, or diabetes have been highly at the risk of this disease. So far, statistics show that only about $2 \%$ of those infected with the disease have died $[8,9]$. Common symptoms of COVID-19 virus include fever and respiratory problems such as dry cough and shortness of breath. In more severe cases, the infection can cause pneumonia, acute respiratory syndrome, kidney failure, and even death [10].

In critical situations, the main goal of hospitals is to achieve the best possible level of health for people in crisis [11]. In the case of the emerging infectious diseases, the intention of nursing to overcome the transmission of the disease is of particular importance because this type of emerging infectious diseases often occur suddenly and cause a lot of pressure and stress on health care providers, especially nurses. The sudden resignation of nurses under the stress of an infectious disease epidemic not only causes a shortage of manpower but also upsets other medical personnel left in the workplace [12, 13]. Without proper medical care guidelines, infectious diseases can spread easily and pose a risk to nurses, which can be prevented to some extend upon proper management [14].

Hospitals need nursing professionalism in an outbreak. With emerging an infectious disease, attention to appropriate facilities and conditions, communication, and medical care and patient satisfaction are raised [12]. Research has shown that various factors can affect the performance of nurses, especially their intention to provide services. Among these factors are the work stress and professionalism of nurses [15, 16], Due to the lack of sufficient information about nurses 'intentions and the factors affecting this practice during the epidemic of COVID-19 and the need to assess the impact of variables such as stress and professionalism on nurses' intentions [2]. On this basis, the present study aimed to determine the status of intentions, stress, and professionalism in nurses and designed the factors affecting the intention of nurses in Iran.

\section{Materials and methods}

\subsection{Study design and sampling}

This descriptive-analytical cross-sectional study was conducted in 2020 in hospitals devoted to COVID-19 in Iran, in order to investigate the intention, stress, and profession (skills) of nurses from their work experience, by voluntarily completing the prepared questionnaires. Conscious consent in the form of research ethics was obtained from all participants before the start of the study.

In this study, data were collected from across the country ( 4 provinces were randomly selected) by using cluster sampling method. Iranian universities of medical sciences were initially known as the first sampling cluster. Among the universities, four universities were randomly chosen. A COVID-19 care reference hospital was chosen from within the universities. The sample size was estimated from the total and randomly chosen from within each hospital, based on the number of nurse employees. The study sample was randomly selected from nurses working in center COVID-19-devoted hospitals from selected provinces. In order to calculate the sample size while determining the size of the community of nurses working in the studied hospitals, using the Cochran's formula, 362 nurses were included in the study.

$$
n=\frac{\frac{z^{2} p q}{d^{2}}}{1+\frac{1}{N}\left[\frac{z^{2} p q}{d^{2}}-1\right]} \cong 362
$$

The criteria were the inclusion of (i) the nurses working at the central hospital for COVID-19, (ii) nurses working in an ICU and emergency setting, and (iii) nurses working in infectious disease wards during the epidemic period. Incomplete questionnaires, nurses on duty and volunteer nurses were excluded from the study. 


\subsection{Variables and data gathering tools}

A self-administered electronic-based questionnaire was used for the study, which included 60 questions using the modified form of the previously developed questionnaires. The questionnaire was structured to determine personal and career-related characteristics (nine questions); interactions during the outbreak (five questions); and stress level at the time of the outbreak, nursing professionalism and nursing intention. A five-point Likert scale was used (11/4 strongly disagree, 21/4 disagree, $31 / 4$ undecided, $41 / 4$ agree, and $51 / 4$ strongly agree) to evaluate the level of stress, professionalism in nursing, and nursing intention.

The electronic version of the questionnaires was designed and distributed among the selected universities to be sent to the nurses, which were selected randomly. A mobile number, as well as an e-mail address, asked from all nurses to share the link of the designed questionnaires. Contact information of the studied nurses (phone number) was asked from the recruitment office of the studied hospitals. The link of the electronic version of questionnaires was sent to the nurses by e-mail and WhatsApp than asked the nurses to complete the questionnaire within the next week. If a questionnaire was not completed by a participant within the time period, followed up by a phone call by the trained liaisons. In the case of a person who did not want to complete the questionnaire, another nurse was replaced from the same department with a similar feature.

\subsection{General characteristics}

The general characteristics of the study participants included personal and occupational characteristics. Personal characteristics included: gender, age and marital status. Job-related characteristics included: organizational position (nurse, matron, Nursing Service Management (NSM) or supervisor), province of residence (Ardabil, Gilan, Kerman, Gorgan), monthly income level (less than 20, 20 to 30, 30 to 40, 40 to 50,50 to 60 , more than 60 million rials and I do not want to answer) and has symptoms of the disease after daily contact with suspicious cases (yes, no).

\subsection{Intention questionnaire}

The nursing intention in this study was described as the voluntary and active provision of nursing care in the future for patients with any newly emerging infectious diseases. The tool for Predictive Nursing Intention for SARS Patient Care [17], based on the planned behaviours theory [18], was revised in this study to determine the purpose of providing nursing care to patients with COVID-19; five questions were included regarding positive behavioural beliefs, negative behavioural beliefs, norms, and control beliefs. The questionnaire was translated into Persian by a linguistics expert, so that the meaning of the question did not change, and evaluated for validity by nursing and medical education specialists and the final sentences were modified for better understanding. The highest nursing intention score was 25 , and the higher scores showed a higher degree of potential nursing intention. The Cronbach-alpha coefficient was calculated 0.76 for the nursing intention in this study.

\subsection{Stress questionnaire}

A questionnaire with 12 questions focused on a trauma evaluation [19], and a stress questionnaire produced by the Korean Neuro-Psychiatric Association of Medical Workers Familiar with a MERS outbreak [20] was used to measure the stress levels during the COVID-19 outbreak in this study. Six questions about anxiety, four about alienation and two questions about anger were included in the stress questionnaire. The overall stress score was 60 , and higher scores showed higher stress levels during the COVID-19 outbreak. The Persian version of the questionnaire was provided to the relevant specialists, especially two clinical psychologists with a nursing background, to check the validity. The Cronbach-alpha coefficient was calculated 0.91 for the questionnaire, where this coefficient was calculated about 0.87 by Oh et al. in 2017 [2].

\subsection{Professionalism questionnaire}

The Persian version of Korean Nurses professionalism questionnaire [21] was used in this study, which was edited and used to test professionalism in nursing during MERS outbreak in South Korea by Oh et al. [2]. It included 29 questions about self-esteem, social knowledge, nursing practice integrity, and freedom from work. The median score for nursing professionalism was 145 and higher-value nurses were considered to have higher levels of professionalism. Cronbach was around 0.89 in this study and 0.92 in another study [2]. 


\subsection{Validity and reliability of the questionnaires}

The questionnaires used in the present study were prepared from a study conducted by $\mathrm{Oh}$ et al. on SARS in South Korea [2]. The English version of the questionnaires was received from the author of the article. After obtaining permission from the main compilers of the questionnaires, the questionnaires were translated into Persian according to the protocol. Two people who had sufficient experience and fluency in translating English texts translated the English version of the questionnaires. The Persian version of the questionnaires was re-translated into English by another translator and compared with the original version in terms of similarity. Content validity assesses, as stated in the literature, whether an instrument comprises all the requisite elements sufficiently or exhaustively to reflect the definition being evaluated [22]. The Persian version was prepared and provided to four specialists (an epidemiologist, a doctorate in nursing, a health education specialist and an infectious disease specialist) to equate and modify the questionnaires according to the characteristics of COVID-19. Since the content validity of the questionnaires have been checked by its main manufacturer and the present study has not made any changes in the content (except for the change from SARS to COVID$19)$, so the content validity in the Persian version is the same. The face validity of the Persian version of the questionnaires was assessed by preparing questions about the fluency, transparency and comprehensibility of the questionnaire and also its appropriateness to the cultural conditions of the community. There was not much change in the structure of the questions in terms of face validity and practically no questions were removed from the main questionnaires. The reliability of the questionnaires was performed on 30 nurses from the research environment (Ardabil and Kerman) who were easily selected and available. The Cronbach-alpha coefficient for nursing intention, stress and professionalism was $0.76,0.91$, and 0.89 , respectively.

\subsection{Data analysis}

During the COVID-19 epidemic, $t$-test was used to evaluate data concerning the characteristics and general circumstances of nurses. The mean stress level scores and professionalism in nursing were measured using the Student $t$-test. Variance analysis was used to evaluate nursing attitude by general characteristics and general circumstances, Multiple regression analysis was carried out to analyze the correlation between nursing experience and nursing attitude with respect to stress and professionalism. All statistical analyzes were completed using version 21 of the SPSS program.

\section{Results}

\subsection{Nursing general characteristics}

Table 1 shows the demographic distribution of the studied samples along with the mean and standard deviation of nurses' stress scores by demographic variables. More than $81 \%$ of the participants in this study were female nurses, while the age group of 30 to 39 years had the highest frequency in terms of distribution of participants and only 22 nurses $(6.07 \%)$ in the age group over 50, totally. More than $70 \%$ of the participants were married and $61.3 \%$ were employed as nurses. Income level as one of the economic variables showed that 148 participants $(40.1 \%)$ in the study had an income level of 30 to 40 million rials per month. Out of the total number of participants, only $28.7 \%$ confirmed their participation in training courses to deal with the epidemic of infectious diseases.

\subsection{Nursing intention, professionalism and stress according to general characteristics and condition}

The results showed that the average level of stress among the studied nurses was higher than the standard, so that most nurses reported high level (above 35 ) or very high level of stress (above 40) by demographic characteristics. Besides, a significant difference was observed in some subgroups. (Table 1) Stress levels of men and women in the present study were not significantly different from each other, but younger nurses reported significantly higher levels of stress than older nurses. Married nurses also reported higher levels of stress than single nurses with a significant difference. Regarding nurses' income level, there was no significant difference in terms of stress levels for different tasks, but trained nurses reported significantly lower stress levels than nurses without training in the field of infectious disease epidemics.

In the present study, four dimensions of positive behavioral beliefs, negative behavioral beliefs, mental standards, and control beliefs were examined as 
Table 1

Nursing stress, professionalism, and intention based on general characteristics and conditions during the COVID-19 outbreak (N=362)

\begin{tabular}{|c|c|c|c|c|c|c|c|c|c|c|c|}
\hline \multirow[t]{2}{*}{ Variables } & \multirow[t]{2}{*}{ Categories } & \multirow[t]{2}{*}{$n(\%)$} & \multicolumn{3}{|c|}{ Nursing stress } & \multicolumn{3}{|c|}{ Nursing professionalism } & \multicolumn{3}{|c|}{ Nursing intention } \\
\hline & & & Mean \pm SD & t or F & $p$ & Mean \pm SD & $\mathrm{t}$ or $\mathrm{F}$ & $p$ & Mean \pm SD & $\mathrm{t}$ or $\mathrm{F}$ & $p$ \\
\hline \multirow[t]{2}{*}{ Gender } & Female & $295(81.4)$ & $48.87 \pm 6.02$ & 0.762 & 0.430 & $21.22 \pm 2.88$ & -4.60 & $<001$ & $18.25 \pm 1.75$ & -0.88 & 0.022 \\
\hline & Male & $67(18.6)$ & $47.22 \pm 4.42$ & & & $22.00 \pm 2.85$ & & & $16.01 \pm 1.01$ & & \\
\hline \multirow[t]{4}{*}{ Age } & $20-29$ & 71 (19.6) & $41.39 \pm 8.59$ & 8.21 & $<001$ & $19.39 \pm 2.91$ & 0.653 & 0.582 & $15.91 \pm 2.15$ & 3.36 & 0.151 \\
\hline & $30-39$ & $139(38.3)$ & $38.46 \pm 4.71$ & & & $21.11 \pm 2.29$ & & & $17.08 \pm 2.33$ & & \\
\hline & $40-49$ & $130(35.9)$ & $38.74 \pm 3.80$ & & & $21.73 \pm 3.22$ & & & $17.52 \pm 1.13$ & & \\
\hline & $\geq 50$ & $22(6.07)$ & $35.90 \pm 2.64$ & & & $22.72 \pm 2.65$ & & & $18.01 \pm 2.53$ & & \\
\hline \multirow[t]{3}{*}{ Marital status } & Single & 68 (18.7) & $41.59 \pm 7.02$ & -5.27 & $<0.001$ & $21.41 \pm 2.74$ & 1.357 & 0.245 & $16.24 \pm 2.51$ & -1.78 & 0.002 \\
\hline & Married & $257(70.1)$ & $39.83 \pm 3.15$ & & & $22.95 \pm 3.03$ & & & $18.02 \pm 1.78$ & & \\
\hline & Other & $37(10.2)$ & $36.55 \pm 8.71$ & & & $23.4 \pm 2.38$ & & & $17.13 \pm 2.07$ & & \\
\hline \multirow[t]{4}{*}{ Income level $^{a}$} & $2-2.9$ & $106(28.7)$ & $41.29 \pm 6.82$ & 1.82 & 0.142 & $19.42 \pm 3.26$ & 7.09 & $<0.001$ & $16.12 \pm 2.16$ & 0.14 & 0.216 \\
\hline & $3-3.9$ & $148(40.1)$ & $38.11 \pm 4.08$ & & & $20.84 \pm 2.75$ & & & $17.04 \pm 2.05$ & & \\
\hline & $4-4.9$ & $26(7.18)$ & $36.01 \pm 5.66$ & & & $21.53 \pm 2.13$ & & & $17.38 \pm 1.98$ & & \\
\hline & $\geq 5$ & $52(14.1)$ & $34.61 \pm 3.92$ & & & $22.30 \pm 2.05$ & & & $17.98 \pm 2.81$ & & \\
\hline \multirow[t]{3}{*}{ Position } & Nurse & $222(61.3)$ & $38.17 \pm 4.33$ & 1.40 & 0.246 & $21.53 \pm 2.92$ & 12.75 & 0.112 & $16.93 \pm 2.06$ & -0.46 & 0.517 \\
\hline & Matron & $98(27.07)$ & $38.87 \pm 4.91$ & & & $20.62 \pm 1.83$ & & & $17.04 \pm 1.11$ & & \\
\hline & $\mathrm{NSM}^{\mathrm{b}}$ or Supervisor & $42(11.6)$ & $39.80 \pm 6.98$ & & & $20.76 \pm 3.12$ & & & $17.43 \pm 2.34$ & & \\
\hline \multirow[t]{2}{*}{ Training ${ }^{c}$} & No & $104(28.7)$ & $34.63 \pm 5.41$ & -5.11 & $<0.001$ & $20.35 \pm 2.34$ & 6.101 & $<0.001$ & $16.31 \pm 2.04$ & 9.42 & $<0.001$ \\
\hline & Yes & $258(71.2)$ & $41.84 \pm 4.48$ & & & $22.68 \pm 3.03$ & & & $17.95 \pm 2.34$ & & \\
\hline
\end{tabular}

Note: $\mathrm{N} / \mathrm{n}=$ Number of participants, $\mathrm{SD}=$ Standard Deviation, $t=t$-test, $f=$ Analysis variance test, $p=P$-value. ${ }^{\mathrm{a}}$ Income was calculated based on Iran currency (Iran Rial, IRR) based on million Rials in a month. ${ }^{\mathrm{b}}$ Nursing Service Management. ${ }^{\mathrm{c}}$ Training courses on epidemic infectious diseases. 
nurses' intentions. Professionalism was studied as another indicator in four dimensions of professional self-concept, social awareness, professionalism of the nursing profession, the role of nursing services and the originality of nursing. Table 1 shows the intention and professionalism of nurses by demographic variables. Nursing intention $(p<0.001, t=4-60)$ was significantly higher in female nurses than male nurses and professionalism $(p<0.001, t=-0.88)$ in male nurses was significantly higher when compared to female nurses. There was no significant difference between the age groups in terms of intention as well as professionalism $(p<0.05)$, while older nurses showed a higher mean of intention and professionalism than younger nurses. According to the results, married nurses had significantly higher intentions than the mean ( $p=0.002, f=-1.78)$, but in terms of professionalism, no significant difference was observed between married nurses and other groups. In contrast, in terms of income level, higher income nurses were significantly more professional $(p<0.001, f=7.09)$ but in terms of nursing intention, no significant difference was observed between higher income nurses and other groups. According to the findings, nurses trained in the epidemic of infectious diseases such as coronary were significantly higher intentions $(p<0.001, t=9.42)$ and professionalism $(p<0.001$, $t=10.10)$ than other nurses.

Table 2

Multiple regression estimates for nursing intention according to general characteristics, stress, and professionalism during the COVID-19 outbreak $(\mathrm{N}=362)$

\begin{tabular}{|c|c|c|c|c|c|}
\hline \multirow{2}{*}{$\begin{array}{l}\text { Explanatory } \\
\text { variables }\end{array}$} & \multirow[t]{2}{*}{$\mathrm{B}$} & \multirow{2}{*}{$\begin{array}{l}\text { Coefficient } \\
\text { std. error }\end{array}$} & \multirow[t]{2}{*}{ S.C $\beta$} & \multicolumn{2}{|c|}{ Contribution } \\
\hline & & & & $\mathrm{t}$ & $p$ \\
\hline \multicolumn{6}{|l|}{$\overline{\text { Age }}$} \\
\hline \multicolumn{6}{|l|}{ 20-29 (ref.) } \\
\hline $30-39$ & 17.023 & 1.199 & 0.737 & 14.194 & $<0.001$ \\
\hline $40-49$ & 11.259 & 1.431 & 0.459 & 7.867 & $<0.001$ \\
\hline 50 and older & 7.499 & 2.440 & 0.153 & 3.073 & 0.002 \\
\hline \multicolumn{6}{|l|}{ Gender } \\
\hline \multicolumn{6}{|l|}{ Female (ref.) } \\
\hline Male & -0.657 & 1.11 & -0.022 & -0.592 & 0.555 \\
\hline \multicolumn{6}{|l|}{ Marital status } \\
\hline \multicolumn{6}{|l|}{ Single (ref.) } \\
\hline Married & -1.630 & 1.174 & -0.056 & -1.389 & 0.166 \\
\hline \multicolumn{6}{|l|}{ Income level $^{a}$} \\
\hline \multicolumn{6}{|l|}{ 2-3 MIRR (ref.) } \\
\hline 3-4 MIRR & -2.095 & 1.055 & -0.092 & -1.987 & 0.048 \\
\hline 4-5 MIRR & 3.027 & 2.276 & 0.069 & 1.330 & 0.185 \\
\hline 5-6 MIRR & 6.987 & 1.816 & 0.239 & 3.847 & $<0.001$ \\
\hline \multicolumn{6}{|l|}{ Position } \\
\hline Nurse & 3.638 & 1.628 & 0.156 & 1.609 & 0.109 \\
\hline Matron (Head Nurse) & -5.246 & 1.225 & -0.204 & -3.222 & $<0.001$ \\
\hline \multicolumn{6}{|l|}{$\mathrm{NSM}^{\mathrm{b}} \$$ supervisor (ref.) } \\
\hline \multicolumn{6}{|l|}{ Previous training ${ }^{c}$} \\
\hline Yes & 3.273 & 1.225 & 0.124 & 2.673 & 0.008 \\
\hline \multicolumn{6}{|l|}{ No (ref.) } \\
\hline \multicolumn{6}{|l|}{ Stress level } \\
\hline \multicolumn{6}{|l|}{ Low (ref.) } \\
\hline Moderate & 18.406 & 2.453 & 0.605 & 7.504 & $<0.001$ \\
\hline High & -14.580 & 2.249 & -0.641 & 6.484 & $<0.001$ \\
\hline Very high & -21.398 & 2.375 & -0.874 & 9.009 & $<0.001$ \\
\hline \multicolumn{6}{|l|}{ Professionalism level } \\
\hline \multicolumn{6}{|l|}{ Low (ref.) } \\
\hline Moderate & 0.368 & 1.232 & 0.013 & 0.299 & 0.765 \\
\hline High & 11.992 & 1.160 & 0.498 & 10.336 & $<0.001$ \\
\hline$\overline{\mathbf{R}}$ & & 0.841 & & & \\
\hline R square & & & 0.707 & & $<0.001$ \\
\hline Adjusted R square & & & 0.689 & & \\
\hline
\end{tabular}

Note: COVID-19 = Coronavirus disease 2019, MIRR = Million Rials in Iran. B = unstandardized regression coefficients, Std. Error $=$ standard error, S.C $\beta=$ standardized regression coefficients. ${ }^{a}$ Income was calculated based on Iran currency (Iran Rial, IRR) based on Million Rials in a month. ${ }^{b}$ Nursing Service management. ${ }^{c}$ Training courses on epidemic infectious diseases. 


\subsection{Relationship between outbreak nursing experience and nursing intention considering stress and professionalism in nursing}

The results of multivariate regression regarding nurses' intentions during the COVID-19 outbreak are presented in Table 2. The results showed that a total of $68.9 \%$ of the variance of nursing intention can be explained by the variables entered in the model (Adjusted R Square $=68.9$ ). According to the results, the most important variables affecting nursing intention were age, income level, previous education about the epidemic of infectious disease, stress level and level of professionalism. Thus, older age had a significant relationship with nursing intention $(p<0.001$, $\mathrm{S} . \mathrm{E}=1.119, B=17.02)$. On the other hand, the results showed that with increasing age, the effect of age on nurses 'intention decreased; and in the age group equal to 50 years $(p=0.002$, S.E $=2.44, B=7.49)$, $15.3 \%$ of nurses' intention could be explained by age. There was no significant relationship between gender and marital status of nurses with nursing intention $(p<0.05)$, but increasing income level was recognized as a variable related to nurses 'intention. Somehow, with increasing income, nurses' intention increased significantly. Stress and professionalism were also identified as effective variables in relation to nursing intention. The results showed that there was a significant and inverse relationship between nursing intention and stress wherein nursing intention was decreased with increasing stress to high levels $(p<0.001$, S.E $=2.37, B=21.39)$. Nevertheless, professionalism showed a significant and positive relationship with nursing intention, so that with increasing nurses' professionalism score, nursing intention was also increased $(p<0.001$, S.E $=1.16$, $B=11.99$ )

\section{Discussion}

During the COVID-19 epidemic, the healthcare workers especially nurses are the first line of defense experienced considerable challenges and increased workload. Nurses caring for patients with COVID-19 are at the high risk of infectious disease [23].The present study examined the level of stress, nursing intention, and professionalism of nurses who worked during the 2020 COVID-19 epidemic in Iran.

Self-efficacy, prior training, and information on the transmission of COVID-19, concerning about spread- ing disease to family, belief in a duty of care, the perceived value of one's response and empathy for patients affect nurses' intentions and willingness to work during epidemics and disasters [24-28]. Therefore, it is vital to understand nurses motivations for willingness to provide nursing care during a pandemic to inform current epidemic planning.

Our study demonstrated that the studied nurses have had positive intentions to provide care to patients with COVID-19. The findings are consistent with those reported by other studies conducted in Taiwan and Australia, which showed that willingness to care during SARS and COVID-19 pandemics ranged from $42.7 \%$ [29] to $61 \%$ care [28]. The mean score of nursing intention in two studies with a similar instrument was high and nursing intention positively correlated with subjective norm, positive perceived behavioral control, attitude toward the behavior and nursing professional values [30,31]. Disease characteristics such as fatality rate, existing of treatment by antiviral agent or vaccine significantly predicted nurses' risk perceptions and their intention [31].

Results from our study showed that factors influencing nurses' intention were stress level, professionalism, as well as age, level of income and knowledge about epidemics and disease. The final model accounted for $68.9 \%$ of the variance in nursing intention to care for patients with COVID-19. Previous studies showed lower $\left(\mathrm{R}^{2}=28.1 \%-55.1 \%\right)$ variance in intention [30, 31].

The present study found that perceived professionalism impacted intention wherein nurse's professionalism was increased as their intention increased. A correlation between nursing intention (willingness to care for patients) and nursing professionalism was also concluded in other studies [31-33]. Patients at critical conditions of COVID-19 require extremely high professional skills of the nurses, reflect the importance of professionalism of nursing. Many factors affect nursing professionalism such as job performance, job satisfaction, organizational commitment, and turnover intention [34]. Nursing shortage and burnout are common staff challenges due to the nature of their profession. Resources and staffing significantly predicted nurses' job satisfaction [35]. To support nurses intention, a variety of measures such as providing and updating knowledge about COVID-19, offering psychological support, strengthening training on professionalism, and reducing the number of stressors should be taken [36]. Moreover, additional interaction with colleagues and being at a healthy workplace can help relieve pressure on nurses and 
alleviate the harmful effects of perceived stress on professional identity [37].

Studies showed that interventions that enhances nursing professionalism would improve clinical performance of nurses and reduce the stress on their clinical practice [38, 39]. After the severe acute respiratory syndrome outbreak, Hong Kong health system developed a hospital authority task force to identify crucial problems in unexpected disasters. To ensure highest standards for quality care, innovative methods with the help of advanced technologies and specialty-training programs need to be implemented [40].

Nurses have experienced emotional anger and frustration with physical stress during the COVID-19 epidemic [2, 41, 42]. Similarly, during the SARS epidemic, although nurses had a commitment to providing care for patients, they had depression, anxiety, and concerns about staying away from their homes [29, 43]. Recently, under the COVID-19 pandemic, higher levels of stress have been reported due to insufficient tools and resources, life-threatening nature of the disease, workload, emotional issues related to contracting COVID-19, and infecting family members [44-47]. The stress of the nurses can cause negative behavioral beliefs, further affect job satisfaction, and reduce professionalism [31-33]. Additional findings from our study showed that a negative correlation emerged between stress and nursing intention. Lord et.al identified that concerning for close family and prevention from further infection could have an effect on their willingness to care [28]. In contrast, a prior study indicated that although nurses had high anxiety and depression, they still show willingness to care for patients [2]. As reported in a systematic review, the sense of confidence in skills, knowledge, safety, and risk perceptions have been identified as enablers for health care workers willingness to care during the pandemic [27]. A healthy workplace with high social capital can mediate nurses perceived stress and improve their professional identity [23]. Providing psychological, social, physical, and family support to HCWs during outbreaks are highlighted in most studies. Psychiatric support, training coping strategies to reduce the negative effects of social isolation are also greatly important [48]. Khee et al. emphasised that developing group session therapies among healthcare providers during the SARS outbreak in Singapore was a source of mutual support for nurses to handle extraordinary challenges of their jobs [49]. Additionally, Chinese government and the private public welfare fund offered free apartments to health care workers to improve their psychological status [46].

Alongside the professionalism and stress, which were the most significant variables among predictor variables, information about epidemics and disease control and prior outbreak nursing experience are associated with increased intention to provide care [2, $28,50,51]$. Results from our study concurs with previous studies wherein nurses with additional knowledge about COVID-19 have had more intention to provide nursing care. Researchers in a previous study showed that nurses' experience of care for SARS patients affected their control beliefs [30]. Therefore, an education program to indirectly experience a pandemic can be helpful for increasing the beliefs that nurses can care for patients to enhance confidence and eventually to strengthen nursing intention. This study also indicated that nursing intention positively correlated with sex as well as income level. Nurses' intention in female nurses and nurses with high income level were high. In a study conducted during the MERS outbreak in Saudi Arabia, receiving financial benefits lowered their stress and encouraged their intention to work in a future pandemic [32]. Providing extra bonus can decrease nurses negative attitudes toward caring for patients with COVID-19 and increase nursing intention [26]. However, some other studies have reported opposite results wherein no difference was reported between willingness of nurses to provide nursing care and demographic variables in H1N1 influenza and COVID-19 [28, 50].

This study had several limitations: First, there was no comparison of nursing professionalism before and after experiencing the outbreak of COVID-19. Second, only some nurses working in the selected university hospitals participated in the study (It is essential to conduct studies involving all nurses who have experienced the outbreak). Third, because the questionnaire used in the study was based on previously designed questionnaires and was revised for study purposes, it could affect the results of the study. Fourth, in this study, we did not perform factor analysis on the questionnaires, because the questionnaires were used previously in a similar disease, which may be recognized as one of the main limitations. Finally, the studied hospitals were sampled, which can limit the generalization of the findings of the present study.

Despite these limitations, the strengths of this study include examining nurses' intentions in responding to future infectious disease outbreaks and examining the stress and occupational status of nurses who expe- 
rienced the outbreak of COVID-19 in 2020, which has led to many deaths and disabilities in the world. No other study examined the level of stress, professionalism, and intent of nurses who experienced its prevalence. These data are essential for infection control measures and the care of patients with any emerging disease in the future.

\section{Conclusion}

The present study showed that nursing experience was of great importance for patients with an emerging infectious disease with the intention of providing care. In addition, a positive relationship was found between nursing intention and professionalism in nursing. However, a negative relationship was identified between nursing intention and stress. Nurses who intend to treat patients with infectious diseases should be on the front line in an emergency. Therefore, it is necessary to collect information about nurses' experience with infectious diseases, as well as regular assessment of job stress and professionalism. It is also important to avoid unprotected placement of nursing staff during an outbreak of infectious disease to improve the quality of medical care and maintain the safety of the nurses themselves. In addition, mechanisms such as designating hospitals as infection management centers or implementing infection prevention training programs are essential for improving professionalism in nursing.

Workplace social capital has a moderating effect on the relationship between perceived stress and professional identity, so more studies are needed to investigate how workplace social capital affects professional identity. Because the continuation of the pandemic is uncertain, having an adequate staff requirement plan, planning appropriate training for nurses, and proactive psychological support are crucial, as proactive psychological support is mandatory to maintain their well-being. Furthermore, providing enough personal protective equipment's (PPEs) can reduce HCWs' fear of self-infection or of infecting their relatives and patients and therefore promote a less stressful approach to the clinical practice.

\section{Acknowledgments}

The authors would like to thank the managers and staffs of all hospitals included in the study for their help in conducting this study.

\section{Conflict of interest}

The authors declare that they have no conflict of interest.

\section{Funding}

This work was funded by the Ardabil University of Medical Sciences (ARUMS). The funder had no role in study design, data analysis, decision to publish, or preparation of the manuscript.

\section{References}

[1] Farid M, Purdy N, Neumann WP. Using system dynamics modelling to show the effect of nurse workload on nurses' health and quality of care. Ergonomics. 2020;63(8):952-64.

[2] Oh N, Hong N, Ryu DH, Bae SG, Kam S, Kim K-Y. Exploring Nursing Intention, Stress, and Professionalism in Response to Infectious Disease Emergencies: The Experience of Local Public Hospital Nurses During the 2015 MERS Outbreak in South Korea. Asian Nursing Research. 2017;11(3):230-6.

[3] Novel CPERE. The epidemiological characteristics of an outbreak of 2019 novel coronavirus diseases (COVID-19) in China. Zhonghua liu xing bing xue za zhi=Zhonghua liuxingbingxue zazhi. 2020;41(2): 145 .

[4] de Groot RJ, Baker SC, Baric RS, Brown CS, Drosten C, Enjuanes L, et al. Commentary: Middle east respiratory syndrome coronavirus (mers-cov): announcement of the coronavirus study group. Journal of virology. 2013;87(14):7790-2.

[5] Van Der Hoek L, Pyrc K, Jebbink MF, Vermeulen-Oost W, Berkhout RJ, Wolthers KC, et al. Identification of a new human coronavirus. Nature medicine. 2004;10(4):368-73.

[6] De Wit E, Rasmussen AL, Falzarano D, Bushmaker T, Feldmann F, Brining DL, et al. Middle East respiratory syndrome coronavirus (MERS-CoV) causes transient lower respiratory tract infection in rhesus macaques. Proceedings of the National Academy of Sciences. 2013;110(41):16598-603.

[7] Chinazzi M, Davis JT, Ajelli M, Gioannini C, Litvinova $\mathrm{M}$, Merler S, et al. The effect of travel restrictions on the spread of the 2019 novel coronavirus (COVID-19) outbreak. Science. 2020;368(6489):395-400.

[8] Stoecklin SB, Rolland P, Silue Y, Mailles A, Campese C, Simondon A, et al. First cases of coronavirus disease 2019 (COVID-19) in France: surveillance, investigations and control measures, January 2020. Eurosurveillance. 2020;25(6):2000094

[9] Zandian H, Sarailoo M, Dargahi S, Gholizadeh H, Vosoughi M, Dargahi A. Evaluation of knowledge and health behavior of university of medical sciences students about the prevention of COVID-19. Work. 2021(Preprint):1-7.

[10] Hosseiny M, Kooraki S, Gholamrezanezhad A, Reddy S, Myers L. Radiology perspective of coronavirus disease 2019 (COVID-19): lessons from severe acute respiratory syndrome and Middle East respiratory syndrome. American Journal of Roentgenology. 2020;214(5): 1078-82. 
[11] Van Keer R-L, Deschepper R, Huyghens L, Bilsen J. Preventing Conflicts Between Nurses and Families of a Multi-ethnic Patient Population During Critical Medical Situations in a Hospital. Journal of Transcultural Nursing. 2020;31(3):250-6.

[12] Organization WH. Home care for patients with suspected novel coronavirus (COVID-19) infection presenting with mild symptoms, and management of their contacts: interim guidance, 04 February 2020. World Health Organization; 2020.

[13] Raeissi P, Zandian H, Mirzarahimy T, Delavari S, Moghadam TZ, Rahimi G. Relationship between communication skills and emotional intelligence among nurses. Nursing Management. 2021;28(2).

[14] Dyo M, Kalowes P, Devries J. Moral distress and intention to leave: a comparison of adult and paediatric nurses by hospital setting. Intensive and Critical Care Nursing. 2016;36:42-8

[15] Choi SO, Kim J. Relationships among job stress, nursing performance, and retention intention of clinical nurses. Journal of Korean Public Health Nursing. 2013;27(1):142-52.

[16] Kwon K-J, Ko K-H, Kim K-W, Kim J-A. The impact of nursing professionalism on the nursing performance and retention intention among psychiatric mental health nurses. Journal of Korean Academy of Nursing Administration. 2010;16(3):229-39.

[17] Yoo HR, Kwon BE, Jang YS, Youn HK. Validity and reliability of an instrument for predictive nursing intention for SARS patient care. Journal of Korean Academy of Nursing. 2005;35(6): 1063-71.

[18] Ajzen I. The theory of planned behavior. Organizational Behavior and Human Decision Processes. 1991;50(2):179211.

[19] DePrince AP, Zurbriggen EL, Chu AT, Smart L. Development of the trauma appraisal questionnaire. Journal of Aggression, Maltreatment \& Trauma. 2010;19(3):275-99.

[20] Korean Neuro-Psychiatric Association. Stress questionnaire for medical workers treated patients with MERS; 2015 Seoul Korean Neuro-Psychiatric Association; 2015 [Available from: http://docs.google.com/forms/d/e/1FAIpQLScj8Ii1vOWjEibwLGPzvuEOe-q2fWi_RPvZH2snkCjcWABA/viewform? $\mathrm{c}=0 \& \mathrm{w}=1 \&$ usp=mail_form_link.

[21] Yeun EJ, Kwon YM, Ahn OH. Development of a nursing professional values scale. Journal of Korean Academy of Nursing. 2005;35(6):1091-100.

[22] Sireci SG. The construct of content validity. Social Indicators Research. 1998;45(1-3):83-117.

[23] Zhang Yd, Gao Yq, Tang Y, Li Yh. The role of workplace social capital on the relationship between perceived stress and professional identity among clinical nurses during the COVID-19 outbreak. Japan Journal of Nursing Science. 2020:e12376.

[24] Chaffee M. Willingness of health care personnel to work in a disaster: an integrative review of the literature. Disaster Medicine and Public Health Preparedness. 2009;3(1):42-56.

[25] Devnani M. Factors associated with the willingness of health care personnel to work during an influenza public health emergency: an integrative review. Prehospital and Disaster Medicine. 2012;27(6):551-66.

[26] Rahmatpour P, Nia HS, Froelicher ES, Kaveh O, Sharif SP, Taghipour B. Psychometric Evaluation of Persian Version of Nurses' Intention to Care Scale (P-NICS) for Patients with COVID-19. International Journal of General Medicine. 2020;13:515.
[27] Aoyagi Y, Beck CR, Dingwall R, Nguyen-Van-Tam JS. Healthcare workers' willingness to work during an influenza pandemic: a systematic review and meta-analysis. Influenza and Other Respiratory Viruses. 2015;9(3):120-30.

[28] Lord H, Loveday C, Moxham L, Fernandez R. Effective communication is key to ICU nurses willingness to provide nursing care amidst the COVID-19 pandemic. Intensive and Critical Care Nursing. 2020:102946.

[29] Ko N-Y, Feng M-C, Chiu D-Y, Wu M-H, Feng J-Y, Pan SM. Applying theory of planned behavior to predict nurses' intention and volunteering to care for SARS patients in southern Taiwan. The Kaohsiung Journal of Medical Sciences. 2004;20(8):389-98.

[30] Jeong SY, Park HS, Wang H-J, Kim M. Intentions to care for new influenza $\mathrm{A}(\mathrm{H} 1 \mathrm{~N}$ 1) patients and influencing factors: an application of theory of planned behavior. Journal of Korean Academic Society of Home Health Care Nursing. 2015;22(1):78-87.

[31] Lee J, Kang SJ. Factors influencing nurses' intention to care for patients with emerging infectious diseases: Application of the theory of planned behavior. Nursing \& Health Sciences. 2020;22(1):82-90.

[32] Khalid I, Khalid TJ, Qabajah MR, Barnard AG, Qushmaq IA. Healthcare workers emotions, perceived stressors and coping strategies during a MERS-CoV outbreak. Clinical Medicine \& Research. 2016;14(1):7-14.

[33] Grimes DE, Mendias EP. Nurses' intentions to respond to bioterrorism and other infectious disease emergencies. Nursing Outlook. 2010;58(1):10-6.

[34] Han S-S, Kim M-H, Yung E-K. Factors affecting nursing professionalism. The Journal of Korean Academic Society of Nursing Education. 2008;14(1):73-9.

[35] CHOI SPP, Cheung K, PANG SMC. Attributes of nursing work environment as predictors of registered nurses' job satisfaction and intention to leave. Journal of Nursing Management. 2013;21(3):429-39.

[36] Wong WC, Wong SY, Lee A, Goggins WB. How to provide an effective primary health care in fighting against severe acute respiratory syndrome: the experiences of two cities. American Journal of Infection Control. 2007;35(1):50-5.

[37] Kılıç E, Altuntaş S. The effect of collegial solidarity among nurses on the organizational climate. International Nursing Review. 2019;66(3):356-65.

[38] Kim H-W, Yoo M-S. The Influences of Nursing Professionalism and Emotional Intelligence on the Clinical Performance Ability in Nursing Students. The Korean Journal of Health Service Management. 2020;14(2):41-54.

[39] Kang M-R, Jeong K-S. Effects of Self-esteem, Nursing Professionalism, Cognitive Emotion Control Strategy on Clinical Practice Stress in Nursing Students. Journal of Digital Convergence. 2020;18(6):353-61.

[40] Wong EM-L, Lau PF. Evolving towards professionalism in emergency nursing in Hong Kong. International Emergency Nursing. 2008;16(1):53-8.

[41] Li L, Ai H, Gao L, Zhou H, Liu X, Zhang Z, et al. Moderating effects of coping on work stress and job performance for nurses in tertiary hospitals: a cross-sectional survey in China. BMC Health Services Research. 2017;17(1):1-8.

[42] Wolf LA, Perhats C, Delao AM, Moon MD, Clark PR, Zavotsky KE. "It'sa burden you carry": describing moral distress in emergency nursing. Journal of Emergency Nursing. 2016;42(1):37-46.

[43] Su T-P, Lien T-C, Yang C-Y, Su YL, Wang J-H, Tsai S-L, et al. Prevalence of psychiatric morbidity and psycholog- 
ical adaptation of the nurses in a structured SARS caring unit during outbreak: a prospective and periodic assessment study in Taiwan. Journal of Psychiatric Research. 2007;41(1-2):119-30.

[44] Vagni M, Maiorano T, Giostra V, Pajardi D. Coping With COVID-19: Emergency Stress, Secondary Trauma and SelfEfficacy in Healthcare and Emergency Workers in Italy. Front Psychol. 2020;11:566912.

[45] Huang JZ, Han M, Luo T, Ren A, Zhou X. Mental health survey of 230 medical staff in a tertiary infectious disease hospital for COVID-19. Zhonghua lao dong wei sheng zhi ye bing za zhi=Zhonghua laodong weisheng zhiyebing zazhi=Chinese journal of industrial hygiene and occupational diseases. 2020;38:E001-E.

[46] Zhongxiang C, Qin C, Zhongchun L, Juanjuan L, Xuan G, Jingfang $L$, et al. Nurses endured high risks of psychological problems under the epidemic of COVID-19 in a longitudinal study in Wuhan China. Journal of Psychiatric Research. 2020.

[47] Lambert VA, Lambert CE, Ito M. Workplace stressors, ways of coping and demographic characteristics as predictors of physical and mental health of Japanese hospital nurses. International Journal of Nursing Studies. 2004;41(1):85-97.

[48] Barello S, Falcó-Pegueroles A, Rosa D, Tolotti A, Graffigna G, Bonetti L. The psychosocial impact of flu influenza pandemics on healthcare workers and lessons learnt for the COVID-19 emergency: a rapid review. International Journal of Public Health. 2020:1-12.

[49] Khee KS, Lee LB, Chai OT, Loong CK, Ming CW, Kheng TH. The psychological impact of SARS on health care providers. Critical Care and Shock. 2004:100-6.

[50] Ma X, He Z, Wang Y, Jiang L, Xu Y, Qian C, et al. Knowledge and attitudes of healthcare workers in Chinese intensive care units regarding 2009 H1N1 influenza pandemic. BMC Infectious Diseases. 2011;11(1):24.

[51] Kwon M. Effects of recognition of flexible work systems, organizational commitment, and quality of life on turnover intentions of healthcare nurses. Technology and Health Care. 2019;27:499-507. 